\title{
Livedoid vasculopathy associated with peripheral neuropathy: a report of two cases
}

\author{
Vasculopatia livedoide associada a neuropatia periférica: relato de dois casos
}

\author{
Mariana Quirino Tubone ${ }^{1}$ \\ Pedro Schestatsky ${ }^{2}$
}

\author{
Gabriela Fortes Escobar ${ }^{1}$ \\ Gabriela Maldonado ${ }^{3}$
}

Juliano Peruzzo ${ }^{1}$

\begin{abstract}
Livedoid vasculopathy (LV) is a chronic and recurrent disease consisting of livedo reticularis and symmetric ulcerations, primarily located on the lower extremities, which heal slowly and leave an atrophic white scar ("atrophie blanche"). Neurological involvment is rare and presumed to be secondary to the ischemia from vascular thrombosis of the vasa nervorum. Laboratory evaluation is needed to exclude secondary causes such as hypercoagulable states, autoimmune disorders and neoplasms. We present two patients with a rare association of peripheral neuropathy and LV, thereby highlighting the importance of a multidisciplinary approach to reach the correct diagnosis.
\end{abstract}

Keywords: Livedo reticularis; Mononeuropathies; Polyneuropathies; Skin diseases, vascular

Resumo: Vasculopatia livedoide é uma doença crônica e recorrente caracterizada por livedo reticular e úlceras simétricas nos membros inferiores, que cicatrizam e deixam uma cicatriz branca atrófica ("atrophie blanche"). Envolvimento neurológico é raro e está provavelmente associado a isquemia pela trombose dos vasa nervorum. Avaliação laboratorial é indicada com o intuito de excluir causas secundárias como estados de hipercoagulabilidade, doenças autoimunes e neoplasias. Apresentamos dois pacientes com uma rara associação de vasculopatia livedoide com neuropatia periférica, enfatizando a importância de uma abordagem multidisciplinar na busca do diagnóstico correto.

Palavras-chave: Dermatopatias vasculares; Livedo reticular; Mononeuropatias; Polineuropatias

\section{INTRODUCTION}

Livedoid vasculopathy (LV) is a chronic and recurrent disease, usually restricted to the skin, and characterized by livedo and ulcerations in the lower extremities. ${ }^{1,2}$ Pain is a common feature and may be secondary to mononeuritis. ${ }^{2}$ In this report we describe two cases of LV associated with peripheral neuropathy, a rare association with few previous reports.

\section{CASE REPORTS}

Case 1: A 58-year-old woman, hypertensive, presented with a 6-month history of painful ulcers in the lower extremities, associated with paresthesia and hypoesthesia in the feet. A biopsy specimen, with rep- resentation of the dermo-hypodermic junction, was compatible with LV. Laboratory evaluations revealed a positive anticardiolipin IgG antibody. Nerve biopsy (sural nerve) showed axonal degenerative alterations, consistent with chronic axonal neuropathy (Figure 1). Electromyography (EMG) demonstrated an axonal polyneuropathy with a sensory predominance.

Case 2: A 46-year-old woman, previously healthy, presented with an episode of syncope, paresis and paresthesia of the extremities. Examination revealed livedo on the distal lower limbs and an ulcer of the medial left malleolus (Figure 2). A deep biopsy

\footnotetext{
Received on 12.12.2012.

Approved by the Advisory Board and accepted for publication on 15.05.2013.

Work performed at the Hospital de Clínicas de Porto Alegre - Federal University of Rio Grande do Sul (HCPA-UFRGS) - Porto Alegre (RS), Brazil. Conflict of interest: None

Financial Support: None

Medical Resident at the Dermatology Service of the Hospital de Clínicas de Porto Alegre - Federal University of Rio Grande do Sul (HCPA - UFRGS) - Porto Alegre (RS), Brazil.

PhD from the Federal University of Rio Grande do Sul (UFRGS) - Adjunct Professor of Internal Medicine, Federal University of Rio Grande do Sul (UFRGS) - Porto Alegre (RS), Brazil.

MSc in Medical Sciences - Dermatology from the Federal University of Rio Grande do Sul - Preceptor at Dermatology Service of the Hospital de Clínicas de Porto Alegre - Federal University of Rio Grande do Sul (HCPA - UFRGS) - Porto Alegre (RS), Brazil. 
specimen revealed thrombotic vasculopathy, suggesting LV (Figure 3). Laboratorial evaluation was normal. EMG demonstrated sensitive and motor axonal neuropathy, with an asymmetric distribution, consistent with mononeuropathy multiplex.

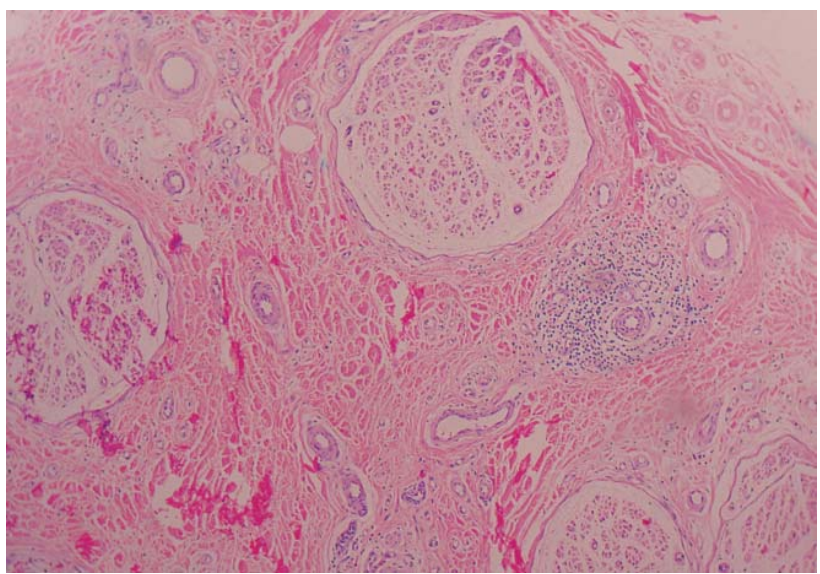

FIGURE 1: Histology of nerve biopsy revealing degenerative alterations and predominantly perivascular inflammatory infiltrate, consistent with chronic neuropathy (H\&E, x100)

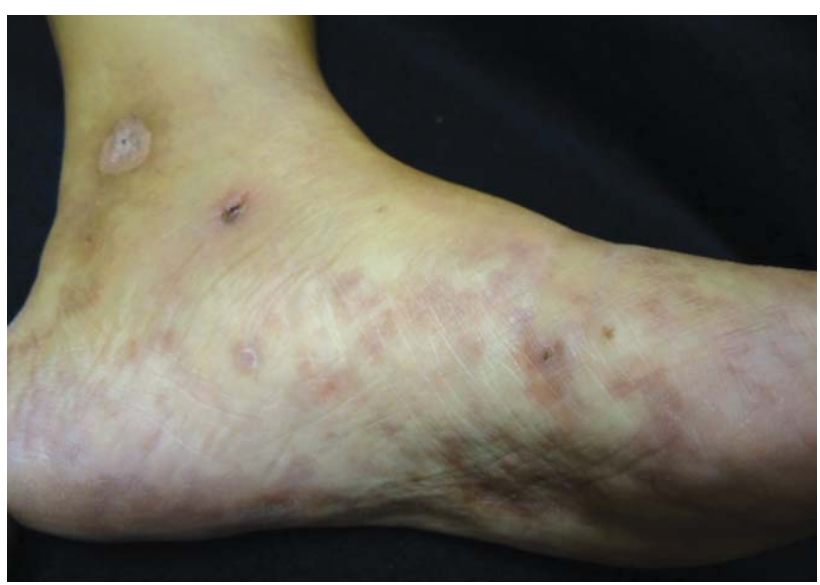

FIGURE 2: Reticulated erythematous-violaceous patches on the left foot and an ulcer in the left medial malleolus

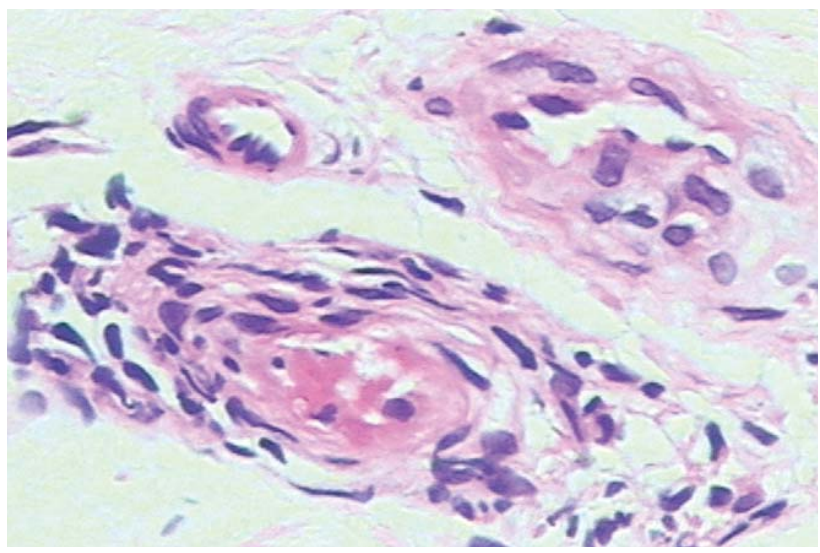

FiguRE 3: Thrombotic vasculopathy with extravasation and secondary inflammatory alterations (H\&E, x400)

\section{DISCUSSION}

$\mathrm{LV}$ is a rare disease, commonly affecting young to middle-aged women, with a female-male ratio of $3: 1.3$. The disorder is believed to be a vasculopathy mediated by a dysfunction of coagulation or fibrinolysis. ${ }^{3}$ The main predisposing factors to thrombosis are endothelial damage, changes in the blood flow and blood disorders leading to hypercoagulability. ${ }^{2}$ There are two forms of the disease: the primary (idiopathic) and the secondary LV, which is associated with hypercoagulable states, autoimmune disorders or neoplasms. ${ }^{1,2,4,5}$

The clinical presentation consists of painful purpuric eruptions and symmetric ulcerations, primarily located on the lower extremities, and overall on the malleoli., ${ }^{3,6}$ After a slow healing process of 3 to 4 months, the lesions leave an atrophic white scar ("atrophie blanche"), which is characteristic, but not pathognomonic, of $\mathrm{LV}^{1-3,5,6}$ Livedo racemosa, defined by the presence of a violaceous netlike pattern of the skin, is commonly present. ${ }^{2,6} \mathrm{LV}$ usually has a chronic course, with outbreaks of varying intensity. ${ }^{1,3}$

Neurological involvement in LV is rare, sparsely reported in the literature. ${ }^{1,4,6,7}$ Sensory symptoms, such as paresthesia or signs such as hyperesthesia usually indicate the presence of mononeuritis multiplex. ${ }^{2}$ The neurological manifestations are presumed to be secondary to the ischemia from vascular thrombosis of the vasa nervorum. ${ }^{2,46}$ The nerve conduction studies show decreased amplitudes of the motor and sensory nerve action potentials with slight reduction of nerve conduction velocities ${ }^{7}$, pointing to an axonal neuropathy of asymmetrical distribution consistent with mononeuritis multiplex. ${ }^{8}$

Nerve biopsy usually reveals endoneurial capillary ectasia and congestion with hemorrhage, with extensive infarct of the peripheral nerve and Schwann cells, resulting in axonal loss without evidence of significant inflammation., ${ }^{4,7}$ The typical histopathologic findings of the skin biopsy are endothelial proliferation, hyaline degeneration and thrombosis of dermal vessels. ${ }^{1,45}$ Absence of inflammation of the vessel wall differentiates LV from true vasculitis., ${ }^{2,-6}$ Direct immunoflourescence usually shows deposition of immunoglobulin, fibrin and complement; however, these findings are not specific for $\mathrm{LV}^{2,5}$

Once the presence of LV is confirmed, a laboratory evaluation is needed in order to exclude secondary causes. ${ }^{2}$ Differential diagnosis is especially made with other causes of leg ulcers, such as chronic venous stasis, leukocytoclastic vasculitis and pyoderma gangrenosum. ${ }^{1,2,5}$ Cutaneous polyarteritis nodosa (PAN) can also produce an identical clinical picture and occasionally cause neurological symptoms. In order to perform a correct differential diagnosis it is necessary 
to obtain an adequate skin sample, with representation from the epidermis to the dermo-hypodermic junction. ${ }^{2,8}$ Vascular involvement in LV usually occurs in the mid and superficial dermis, whereas in PAN histological examination reveals a necrotizing medium-sized vasculitis affecting the reticular dermis and the subcutaneous fat which can cause secondary changes in the superficial dermal vessels. This demonstrates the importance of obtaining a deep skin biopsy. $^{2,8}$ Therefore, Mimiouni et al suggest that after performing a 6-mm punch biopsy, a 4-mm punch should be introduced through the surgical defect in order to reach deeper subcutaneous tissue. Both cylinders are then sent for pathological evaluation. ${ }^{8}$

The treatment of LV is challenging and the therapeutic options are based on case series. The current approach is based on drugs that stimulate endogenous fibrinolytic activity, inhibit thrombus formation or cause vasodilatation. ${ }^{9}$

This report presents two patients with a rare association of neuropathy and LV, highlighting the importance of a multidisciplinary approach to reach the correct diagnosis.

\section{REFERENCES}

1. Hairston BR, Davis MD, Pittelkow MR, Ahmed I. Livedoid vasculopathy: further evidence for procoagulant pathogenesis. Arch Dermatol. 2006;142:1413-8.

2. Criado PR, Rivitti EA, Sotto MN, Valente NY, Aoki V, Carvalho JF, et al. Livedoid vasculopathy: an intringuing cutaneous disease. An Bras Dermatol. 2011;86:961-77.

3. Browning CE, Callen JP. Warfarin therapy for livedoid vasculopathy associated with cryofibrinogenemia and hyperhomocysteinemia. Arch Dermatol. 2006;142:75-8.

4. Toth C, Trotter M, Clark A, Zochodne D. Mononeuropathy multiplex in association with livedoid vasculitis. Muscle Nerve. 2003;28:634-9.

5. Khenifer S, Thomas L, Balme B, Dalle S. Livedoid vasculopathy: thrombotic or Inflammatory disease? Clin Exp Dermatol. 2009;34:e811-3

6. Osada S, Kimura Y, Kawana S. Case of livedoid vasculopathy with peripheral neuropathy successfully treated with low-dose warfarin. J Dermatol. 2010;37:98-101

7. Kim JE, Park SY, Sinn DI, Kim SM, Hong YH, Park KS, et al. Ischemic neuropathy associated with livedoid vasculitis. J Clin Neurol. 2011;7:233-6.

8. Mimouni D, Ng PP, Rencic A, Nikolskaia OV, Bernstein BD, Nousari HC. Cutaneous polyarteritis nodosa in patients presenting with atrophie blanche. $\mathrm{Br} \mathrm{J}$ Dermatol. 2003;148:789-94.

9. Lee JH, Choi HJ, Kim SM, Hann SK, Park YK. Livedoid vasculitis responding to PUVA therapy. Int J Dermatol. 2001;40:153-7.

\author{
MAILING ADDRESS: \\ Juliano Peruzzo \\ Rua Ramiro Barcelos, 2350 - Santa Cecília. \\ 90035-903 - Porto Alegre - RS \\ Brazil \\ E-mail: julianoperuzzo@gmail.com
}

How to cite this article: Tubone MQ, Escobar GF, Peruzzo J, Schestatsky P, Maldonado G. Livedoid vasculopathy associated with peripheral neuropathy: a report of two cases. An Bras Dermatol. 2013;88(6 Suppl 1):S227-9. 